\title{
Vitamin E $\delta$-tocotrienol sensitizes human pancreatic cancer cells to TRAIL-induced apoptosis through proteasome-mediated down-regulation of c-FLIPs
}

Rony A. Francois ${ }^{1 \dagger}$, Anying Zhang ${ }^{1,2 \dagger}$, Kazim Husain ${ }^{1}$, Chen Wang ${ }^{1,3}$, Sean Hutchinson ${ }^{1}$, Michael Kongnyuy ${ }^{1}$, Surinder K. Batra ${ }^{4}$, Domenico Coppola ${ }^{5}$, Said M. Sebti ${ }^{6}$ and Mokenge P. Malafa ${ }^{1,6^{*}}$

\begin{abstract}
Background: Vitamin E $\delta$-tocotrienol (VEDT), a vitamin E compound isolated from sources such as palm fruit and annatto beans, has been reported to have cancer chemopreventive and therapeutic effects.

Methods: We report a novel function of VEDT in augmenting tumor necrosis factor-related apoptosis-inducing ligand- (TRAIL-) induced apoptosis in pancreatic cancer cells. The effects of VEDT were shown by its ability to trigger caspase-8-dependent apoptosis in pancreatic cancer cells.

Results: When combined with TRAIL, VEDT significantly augmented TRAIL-induced apoptosis of pancreatic cancer cells. VEDT decreased cellular FLICE inhibitory protein (c-FLIP) levels without consistently modulating the expression of decoy death receptors 1, 2, 3 or death receptors 4 and 5 . Enforced expression of c-FLIP substantially attenuated VEDT/ TRAIL-induced apoptosis. Thus, c-FLIP reduction plays an important part in mediating VEDT/TRAIL-induced apoptosis. Moreover, VEDT increased c-FLIP ubiquitination and degradation but did not affect its transcription, suggesting that VEDT decreases c-FLIP levels through promoting its degradation. Of note, degradation of c-FLIP and enhanced TRAILinduced apoptosis in pancreatic cancer cells were observed only with the anticancer bioactive vitamin $E$ compounds $\delta-, \gamma^{-}$, and $\beta$-tocotrienol but not with the anticancer inactive vitamin $E$ compounds $\alpha$-tocotrienol and $\alpha-, \beta-, \gamma^{-}$, and $\delta$-tocopherol.
\end{abstract}

Conclusions: C-FLIP degradation is a key event for death receptor-induced apoptosis by anticancer bioactive vitamin E compounds in pancreatic cancer cells. Moreover, VEDT augmented TRAIL inhibition of pancreatic tumor growth and induction of apoptosis in vivo. Combination therapy with TRAIL agonists and bioactive vitamin E compounds may offer a novel strategy for pancreatic cancer intervention.

Keywords: $\delta$-Tocotrienol, Pancreatic cancer, Apoptosis, TRAIL, c-FLIP

\footnotetext{
*Correspondence: mokenge.malafa@moffitt.org

${ }^{\dagger}$ Rony A. Francois and Anying Zhang contributed equally to this work

${ }^{1}$ Gastrointestinal Oncology Program, Department of Gastrointestinal Oncology, H. Lee Moffitt Cancer Center and Research Institute, 12902

Magnolia Drive, Tampa, FL 33612, USA

Full list of author information is available at the end of the article
} 


\section{Background}

Pancreatic ductal adenocarcinoma represents a major healthcare problem, with a high fatality rate and increasing incidence, and is likely to increase from the fourthto the second-leading cause of cancer deaths in the US by 2030 [1-4]. Escape from apoptosis (programed cell death) is a characteristic of pancreatic cancer cells, contributing to their resistance to currently available interventions $[5,6]$. Therefore, targeting apoptosis resistance is an important strategy to improve pancreatic cancer outcomes.

Apoptosis is controlled by 2 major signaling pathways: the extrinsic pathway, initiated by death receptors, and the intrinsic pathway, initiated via the mitochondria $[7,8]$. Crosstalk between these 2 pathways is mediated by signaling involving the proapoptotic protein Bid [9]. The activation of the extrinsic death receptor-mediated apoptosis pathway relies on a death ligand (e.g., tumor necrosis factor-related apoptosis-inducing ligand [TRAIL]) binding to its corresponding death receptors [10]. Activation of the extrinsic death receptor-mediated apoptotic pathway has received attention as a potential strategy for cancer treatment because its activation preferentially induces apoptosis in transformed or malignant cells but not in most normal cells. Recombinant human TRAIL and the agonist antibodies against death receptor 4 (DR4) and death receptor 5 (DR5), which directly activate extrinsic apoptotic pathways, are being tested in early-phase clinical trials. However, recent studies have shown that many types of cancer cells, including pancreatic ductal adenocarcinoma cells, are resistant to the apoptotic effects of TRAIL [11-13], suggesting that treatment with TRAIL alone may not be sufficient for treating pancreatic cancer. Therefore, sensitizers capable of overcoming TRAIL resistance in pancreatic cancer cells are needed to establish more effective TRAIL-based pancreatic cancer therapies.

Tocotrienols $\left(\alpha-, \beta-, \delta_{-}\right.$, and $\left.\gamma^{-}\right)$are 1 of 2 groups of compounds that constitute the vitamin E family [14]. The $\beta-, \delta$-, and $\gamma$-tocotrienols have shown promising efficacy in preventing and treating human cancers, including pancreatic cancer [15-18]. Vitamin E delta-tocotrienol (VEDT) is undergoing early-phase human clinical trials for pancreatic cancer intervention. VEDT exhibits pleiotropic pancreatic anticancer effects, including induction of cell cycle arrest and apoptosis [16, 19] and prevention of angiogenesis and invasion [20-22], demonstrating VEDT's potential utility as a pancreatic anticancer drug. VEDT also augments gemcitabine activity in pancreatic cancer, suggesting its potentiality as an adjunct in combination therapy. Multiple targets, including $\mathrm{p} 27$, $\mathrm{K}$-ras, p53, NF-kB, and VEGF, have been proposed to explain the anticancer effects of VEDT [16, 19-22], but the underlying molecular mechanisms have not yet been fully elucidated.

Here, we show for the first time that VEDT effectively sensitizes pancreatic cancer cells but not human pancreatic ductal epithelial cells to TRAIL-induced apoptosis, suggesting that this combined treatment may provide a safe and effective therapeutic strategy against pancreatic cancer. Furthermore, we provide novel evidence that the prominent sensitizing effect of VEDT on TRAIL-induced apoptosis is primarily through inducing cellular FLICE inhibitory protein (c-FLIP) degradation. Thus our findings highlight a novel mechanism by which VEDT modulates apoptosis in human cancer cells.

\section{Methods and materials}

\section{Ethics statement}

All experiments were carried out in accordance with guidelines set by the Animal Experimental Ethics Committee.

\section{Chemicals and reagents}

Vitamin $E$ analogs $\alpha-, \beta-, \gamma^{-}$, and $\delta$-tocopherols and tocotrienols were kindly gifted by Davos Life Sciences (Helios, Singapore). Ethanol was purchased from Aaper Alcohol \& Chemical (Shelbyville, KY). Recombinant human TRAIL was purchased from Invitrogen (Carlsbad, CA). FLICE inhibitory protein (FLIP) antibody (NF6) was purchased from Alexis Biochemicals (Enzo Life Sciences, Farmingdale, NY). DR5, DR4, DCR1, DCR2, and DCR3 antibodies were purchased from Abcam (Cambridge, MA). Caspase-3 (\#9662), caspase-8 (\#9746), PARP (\#9542), cleaved caspase 3 (\#9661S), cleaved caspase 8 (\#9496), cleaved PARP (\#5625), and green fluorescence protein (GFP) antibodies were purchased from Cell Signaling Technology (Beverly, MA). Hemagglutinin(HA-) probe antibody, protein A/G PLUS-Agarose, and secondary antibodies were purchased from Santa Cruz Biotechnology (Santa Cruz, CA). All cDNA plasmids were purchased from Origene (Rockville, MD). The sulforhodamine B- (SRB-) based In Vitro Toxicology Assay Kit and all other reagents were purchased from SigmaAldrich (St. Louis, MO) unless otherwise specified.

\section{Cell lines and culture conditions}

AsPc-1, BxPc-3, MiaPaCa-2, PANC-1, and SW1990 human pancreatic cancer cell lines (American Type Culture Collection, Manassas, VA) were cultured in complete $1 \times$ Dulbecco's Modified Eagle Medium (DMEM; Invitrogen) supplemented with $10 \%$ fetal bovine serum (HyClone, Logan, UT), penicillin-streptomycin (Mediatech, Herndon, VA) at a final concentration of $50 \mathrm{IU} /$ $\mathrm{mL}$ (penicillin), $50 \mathrm{mg} / \mathrm{mL}$ (streptomycin), and $2 \mathrm{mM}$ L-glutamine (Mediatech). AsPc-1 and BxPc-3 cells were 
cultured in complete RPMI 1640 medium (Invitrogen) containing $10 \%$ fetal bovine serum, penicillin-streptomycin, $10 \mathrm{mM}$ HEPES buffer (Mediatech), $1 \mathrm{mM}$ sodium pyruvate (Invitrogen), and $2 \mathrm{mM} \mathrm{L}$-glutamine (Mediatech). HPDE6-C7 human pancreatic ductal epithelial cells (gift from G. Springett, Moffitt Cancer Center) were cultured in keratinocyte serum-free medium (Invitrogen) containing the provided epidermal growth factor and bovine pituitary extract supplements. Immortalized human pancreatic normal epithelial (HPNE) cells (gift from P. Campbell, Moffitt Cancer Center) were cultured in a mixture of DMEM and M3:F media (INCELL, San Antonio, TX) at a ratio of 3 parts DMEM and 1 part M3:F media and were supplemented with $5 \%$ fetal bovine serum. All cell lines were maintained at $37^{\circ} \mathrm{C}$ in a humidified incubator with $5 \% \mathrm{CO}_{2}$. Cells were passaged regularly with $.05 \%$ trypsin-ethylenediaminetetraacetic acid (Invitrogen) to maintain logarithmic-phase growth. For all experiments, cells were gently detached with Accutase enzyme cell detachment medium (eBioscience, San Diego, CA) in accordance with the provided protocol, with Trypan Blue and hemacytometer used to determine viable cell number.

\section{Cell viability and cell survival assay}

Cells were seeded in 96-well plates at a density of 3000 cells/well and allowed to attach overnight. After cells were incubated for $72 \mathrm{~h}$ with various concentrations of drugs $\left(10^{-5}\right.$ to $\left.10^{-4} \mathrm{M}\right)$ or ethanol $(<5 \%)$ as vehicle control, media were aspirated and replaced with $20 \mu \mathrm{L}$ of $1 \mathrm{mg} / \mathrm{mL}$ MTT (3-[4,5-dimethylthiazol-2-yl]-2,5-diphenyltetrazolium bromide) and incubated for 2 to $4 \mathrm{~h}$ at $37{ }^{\circ} \mathrm{C}$ in a humidified atmosphere of $5 \% \mathrm{CO}_{2}$. Media were aspirated, $200 \mu \mathrm{L}$ of dimethyl sulfoxide were added to each well, plates were incubated for $5 \mathrm{~min}$ with shaking, and absorbance was read at $540 \mathrm{~nm}$. Cell survival was determined using the SRB colorimetric assay for cytotoxicity in accordance with manufacturer's instructions. The SRB assay is an established surrogate for cell survival [23]. Absorbance was recorded using a microplate reader at $565 \mathrm{~nm}$.

\section{Determination of apoptosis}

Cells $\left(1 \times 10^{6}\right)$ were seeded in $100-\mathrm{mm}$ tissue culture dishes and allowed to adhere overnight. Cells were treated the following day at varying doses with $\delta$-tocotrienol and collected at specific time points to assess apoptosis by either terminal deoxynucleotidyl transferase-mediated nick end labeling (TUNEL) or annexin V staining. Cells were washed with phosphatebuffered saline (PBS), pelleted, and counted using a hemacytometer. For all TUNEL experiments, $\sim 1 \times 10^{5}$ cells were fixed onto a glass slide using a Cytospin III centrifuge (Thermo Shandon Inc., Pittsburgh, PA) and then fixed in $4 \%$ paraformaldehyde in PBS solution overnight at $4{ }^{\circ} \mathrm{C}$. Cells were made permeable the next day via incubation in $0.1 \%$ sodium citrate- $0.1 \%$ Triton $\mathrm{X}-100$ solution at $4{ }^{\circ} \mathrm{C}$ for $2 \mathrm{~min}$ and then labeled for apoptotic DNA strand breaks using the in situ cell death detection kit, AP (Roche Applied Science, Indianapolis, IN) in accordance with manufacturer's instructions. Cells were stained in Vectashield mounting medium (Vector Laboratories, Burlingame, CA) containing DAPI (4,6-diamidino-2-phenylindole) to counterstain DNA. Fluorescein-labeled DNA strand breaks (TUNEL-positive cells) were then visualized using a fluorescence microscope (Leica Microsystems Inc., Bannockburn, IL), and 5 representative pictures of the slide field were taken with a digital camera (Diagnostic Instruments, Inc., Sterling Heights, MI). TUNEL-positive nuclei (green) were scored and compared with DAPI-stained nuclei (blue) to determine the induction percentage of apoptosis for each treatment group. Annexin V and propidium iodide staining were performed with the Annexin V-FITC Apoptosis Detection Kit I (BD Biosciences) as follows: pelleted cells were washed twice with cold PBS and then briefly resuspended in a $1 \times$ binding buffer before incubation with annexin V-FITC and propidium iodide according to the manufacturer's instructions. Flow cytometry was performed using a FACScan flow cytometer (BectonDickinson), with analysis using FLOW-JO software (Tree Star, Ashland, OR) to assess the Annexin-positive cell population.

\section{Caspase enzymatic activity assay and use of irreversible caspase inhibitors}

Enzymatic activities of caspases-3, -8, and -9 were determined using each respective fluorogenic substrate (Calbiochem, EMD Biosciences, San Diego, CA). Protein extract $(20 \mu \mathrm{g})$ was incubated in a reaction buffer containing $50 \mathrm{mM}$ Tris $(\mathrm{pH} 7.5)$ and caspase substrate at a final concentration of $20 \mu \mathrm{M}$ in 96 -well plates. After 3-h incubation at $37{ }^{\circ} \mathrm{C}$, liberated fluorescent 7-amido-4-methyl-coumarin groups were quantified using a multi-well plate VersaFluorTM Fluorometer with an excitation filter of $380 \mathrm{~nm}$ and an emission filter of $460 \mathrm{~nm}$ (Bio-Rad Laboratories, Hercules, CA). When irreversible inhibitors of caspases-3, -8 , and -9 were used (Calbiochem, EMD Biosciences), each inhibitor was used at a final concentration of $10 \mu \mathrm{M}$ and incubated with the treatment group $4 \mathrm{~h}$ before treatment with tocotrienol. Tocotrienol was then added to the media containing the inhibitor at the indicated final concentration and treated for the desired length of time. 


\section{Western blot analysis}

To prepare whole cell protein lysates, cells were seeded at $1 \times 10^{6}$ cells per $100-\mathrm{mm}$ tissue culture dish and treated the following day with $\delta$-tocotrienol. After desired treatment times, cells were collected, washed with PBS, pelleted, lysed on ice for $5 \mathrm{~min}$, and then stored at $-20^{\circ} \mathrm{C}$. Tumor tissues were cut into small pieces and homogenized with tissue protein extraction reagent (T-PER, Pierce) and centrifuged at $10000 \mathrm{RPM}$ for $10 \mathrm{~min}$. The extracted proteins were stored at $-20^{\circ} \mathrm{C}$. Protein concentration was determined to ensure equal protein loading. Protein extracts were resolved using a $12.5 \%$ SDS-PAGE gel and then transferred to nitrocellulose membrane. Protein separation was briefly assessed using Ponceau $\mathrm{S}$ solution (Pierce). Membranes were then washed with fresh Tris-buffered saline containing .1\% Tween $20(1 \times$ TBS-T) and blocked with 5\% nonfat dry milk solution. Primary antibodies were incubated in 3\% BSA solution either overnight at $4{ }^{\circ} \mathrm{C}$ or for $1 \mathrm{~h}$ at $25{ }^{\circ} \mathrm{C}$. When reblotting was necessary, antibodies were stripped from membrane by incubating with Western blot stripping buffer (Pierce) for $0.5 \mathrm{~h}$ at $25^{\circ} \mathrm{C}$. High-affinity antibodies were stripped from membrane by washing for $5 \mathrm{~min}$ with a $0.2 \mathrm{M} \mathrm{NaOH}$ solution 3 times at $25^{\circ} \mathrm{C}$, followed by $3 \times 5$-min washes with deionized water. Membranes were thoroughly washed in $1 \times$ TBS-T at $25{ }^{\circ} \mathrm{C}$ and incubated with secondary antibody (horseradish peroxidase-conjugated) at 1:2000 dilutions for $1 \mathrm{~h}$ at room temperature. The washed blot was then treated with SuperSignal West Pico chemiluminescent substrate (Pierce Biotech) for positive antibody reaction. Membranes were exposed to $\mathrm{x}$-ray film for visualization and densitometric quantization of protein bands using AlphaEaseFC software (Alpha Innotech, Santa Clara, CA).

\section{Generation of MiaPaCa-2 cells stably expressing GFP-labeled c-FLIP}

MiaPaCa-2 cells were transfected with a plasmid-containing full-length open-reading frame cDNA of c-FLIP fused with GFP at the C-terminus in a pCMV6-AC-GFP vector. $\mathrm{MiaPaCa}-2$ cells transfected with the pCMV6AC-GFP vector containing GFP alone served as control. All transfections were performed using Lipofectamine ${ }^{\text {тм }}$ 2000 reagent (Invitrogen) at a $1 \mu \mathrm{g}: 1 \mu \mathrm{L}$ DNA-to-Lipofectamine 2000 ratio, per manufacturer's instructions. Cells were selected for 2 weeks with G418 sulfate at a final concentration of $500 \mu \mathrm{g} / \mathrm{mL}$.

Immunoprecipitation for detection of c-FLIP ubiquitination Mia-FLIP ${ }_{s}$ cells, stably expressing GFP-FLIP , were transfected with HA-ubiquitin plasmid (Addgene) using the Lipofectamine 2000 transfection reagent, in accordance with the manufacturer's instructions. After $24 \mathrm{~h}$, cells were treated with $\delta$-tocotrienol alone $(50 \mu \mathrm{M})$ or in combination with MG-132 $(25 \mu \mathrm{M})$ for $6 \mathrm{~h}$ and then lysed for immunoprecipitation of ubiquitin-bound c-FLIP, using GFP polyclonal antibody (Abcam). Harvested cells were washed 3 times with ice-cold PBS and resuspended in $1 \mathrm{~mL}$ of ice-cold CelLytic ${ }^{\mathrm{TM}} \mathrm{M}$ cell lysis reagent (Sigma) containing protease inhibitors. Cleared lysates were then incubated with $10 \mu \mathrm{g}$ of GFP polyclonal antibody and $100 \mu \mathrm{L}$ of $50 \%$ slurry of Protein A/G Agarose (Santa Cruz, sc-2003) into the lysate, and the mixture was rotated overnight at $4{ }^{\circ} \mathrm{C}$. Beads were washed three times with lysate buffer followed by spinning for $5 \mathrm{~s}$ at 10,000 $\mathrm{g}$. After the washes, $50 \mu \mathrm{L}$ of $1 \times$ sample buffer was added to the bead pellet and boiled at $100{ }^{\circ} \mathrm{C}$ for $5 \mathrm{~min}$ followed by the detection of ubiquitin-bound c-FLIP ${ }_{s}$ with Western blotting using anti-HA antibody (Santa Cruz, sc-57592).

\section{Quantitative PCR analysis}

RNA was isolated from cells using the AllPrep RNA/Protein kit from Qiagen (Germantown, MD), in accordance with the manufacturer's instructions. RNA extracts were analyzed by quantitative PCR by the Molecular Biology Core at the Moffitt Cancer Center using the TaqMan gene expression assay kit to assess c-FLIP mRNA levels. $18 \mathrm{~S}$ rRNA was used as an internal control.

\section{In vivo tumor xenograft model}

MiaPaCa-2 cells were harvested and resuspended in fresh media, and the number of viable cells was determined. Cells were then injected subcutaneously into flanks of NIH-III nude SCID mice (Charles River Laboratories, Boston, MA) at a density of $1 \times 10^{6}$ cells/per flank in a 1:1 solution of PBS to Matrigel Matrix (BD BioSciences). Mice were randomized into control and treated groups, with controls receiving ethanol-extracted olive oil (vehicle control) alone and treated mice receiving $200 \mathrm{mg} / \mathrm{kg}$ of $\delta$-tocotrienol in vehicle. All treatments were administered orally by gavage 12 times/week (weekdays, $2 \times$ /day; weekends, $1 \times /$ day), and mouse weights were recorded twice per week.

For the drug combination (TRAIL and VEDT) experiment, female Athymic nude mice $(n=20)$ were injected subcutaneously with MiaPaCa-2 cells into flanks at a density of $1 \times 10^{6}$ cells/per flank in a $1: 1$ solution of PBS to Matrigel Matrix. Mice were randomized into 4 groups of 5 animals each and treated as follows: (Group 1) Vehicle control mice were given orally ethanol-extracted olive oil twice a day and intraperitoneal (IP) injection of PBS on alternate days for 4 weeks, (Group 2) TRAIL mice were injected with TRAIL $20 \mu \mathrm{g} / \mathrm{kg}$ IP on alternate days for 4 weeks, (Group 3) VEDT mice were given orally VEDT (200 mg/kg) twice a day for 4 weeks, and (Group 4) TRAIL + VEDT mice were injected with TRAIL $20 \mu \mathrm{g} / \mathrm{kg}$ 
IP on alternate days and VEDT orally $(200 \mathrm{mg} / \mathrm{kg})$ twice a day for 4 weeks. Tumors were measured daily with calipers using the formula $\mathrm{T}=\mathrm{L} \times \mathrm{W} \times[(\mathrm{L}+\mathrm{W}) / 2] \times 0.5236$, where $\mathrm{T}$ is tumor volume, $\mathrm{L}$ is smallest tumor diameter, and $\mathrm{W}$ is largest tumor diameter. Animal data are representative of 2 independent experiments. Animals were sacrificed after 4 weeks and tumor weights were recorded and half tumor tissues were fixed in buffered formalin for histology staining and the other half were immersed in liquid nitrogen then frozen at $-80{ }^{\circ} \mathrm{C}$ for further biochemical analyses.

\section{Histological and immunohistochemical analyses}

At the end of the study, mice were killed, and tumors were extracted and embedded in paraffin sections for further analyses. Immunohistochemistry was performed using the Ventana Discovery XT automated system (Ventana Medical Systems, Tucson, AZ), per manufacturer's protocol, with proprietary reagents. Slides were deparaffinized on the automated system with EZ Prep solution. Sections were heated for antigen retrieval. For immunohistochemistry, tissue sections were incubated with antibodies. Detection was performed using the Ventana OmniMap kit. Apoptosis by TUNEL staining, cleaved caspase-8, cleaved caspase-3, and Ki-67 staining and hematoxylin and eosin staining were quantified by the Moffitt Anatomic Pathology Core.

\section{Statistical analyses}

Data, expressed as mean \pm standard error of the means, were analyzed statistically using unpaired $t$-tests or 1-way analysis of variance (ANOVA), as appropriate. ANOVA was followed by Duncan's multiple range tests using SAS statistical software for comparisons between different treatment groups. Analyses of in vivo data were performed using the GraphPad Prism program (GraphPad Software, San Diego, CA) on the entire tumor growth curve using a 2-way ANOVA, mixed-effect model for repeated measures, with respect to the column factor corresponding to $\delta$-tocotrienol treatment. Statistical significance was set at $P<.05$.

\section{Results}

VEDT inhibits the growth of human pancreatic cancer cells in vitro and in vivo and induces apoptosis

We first examined whether VEDT alone could inhibit the survival of a panel of human pancreatic cancer cells. Immortalized HPNE cells and HPNE cells transformed with oncogenic K-Ras (HPNE K-Ras) served as controls. VEDT significantly inhibited the viability of 5 human pancreatic cancer cell lines and the HPNE K-Ras cell line in a dose-dependent manner. In contrast, HPNE cells were markedly less sensitive to VEDT (Fig. 1a).
Because decreased cell survival may be caused by many processes (i.e., autophagy, anoikis, apoptosis, necrosis), we next investigated whether VEDT survival inhibition could be attributed to increased apoptosis. Using TUNEL staining, which detects apoptotic DNA fragmentation, we examined VEDT's ability to induce apoptosis in MiaPaCa-2 cells. VEDT administration resulted in a statistically significant $(P<.001)$ induction of apoptosis in MiaPaCa-2 cells (Fig. 1b). In contrast, normal HPDE6-C7 cells were spared from apoptotic cell death at the equivalent dose of $20 \mu \mathrm{M}$, indicating that VEDT selectively exhibits activity against malignantly transformed cells. To verify these findings in vivo, we examined the proapoptotic activity of VEDT in a human pancreatic cancer xenograft mouse model, as described previously [16]. MiaPaCa-2 cells were injected subcutaneously into NIH-III nude mice and allowed to reach a volume of $100 \mathrm{~mm}^{3}$. Immunohistochemistry of paraffin-embedded tumors of treated mice showed that VEDT not only caused a statistically significant inhibition of tumor growth compared with vehicle $(P<.007)$ but also resulted in significant $(P<.05)$ induction of apoptosis in tumor tissues (Fig. 1c, d).

\section{VEDT induces caspase-8-dependent apoptosis in human pancreatic cancer cells}

To determine the mechanism by which VEDT induces apoptosis in pancreatic cancer cells, we measured VEDT's effects on the activation of intracellular caspase cascades and the dependence of VEDT-induced apoptosis on caspase activation. Cleavage of procaspase- 8 and procaspase- 3 were detected in VEDT-treated MiaPaCa-2, BxPC-3, and SW1990 cell lines. Although procaspase- 9 was detected in these cells, cleavage of procaspase-9 was not detected (Fig. 2a). Consistent with the immunoblot detection, caspase- 8 and caspase-3 enzyme activities were both increased from 6 to $24 \mathrm{~h}$ following VEDT treatment in MiaPaCa-2 cells; however, caspase- 9 activity was not significantly altered after VEDT treatment (Fig. 2b). Furthermore, as shown in Fig. 3c, inhibition of caspase- 8 and caspase-3 activation using $\mathrm{Z}$-Ile-Glu(OMe)-Thr-Asp(OMe)-CH2F and Ac-Asp-Glu-Val-Asp-CMK resulted in significant inhibition of VEDT-induced apoptosis in MiaPaCa-2 cells, whereas inhibition of caspase- 9 activation using Z-Leu-Glu(OMe)-His-Asp(OMe)-CH2F resulted in no effect on VEDT-induced apoptosis in these cells. Moreover, significant induction of cleaved caspase- 3 was also detected in MiaPaCa-2 xenograft tumors treated with VEDT (Fig. 2d). Thus, these results collectively show that VEDT induces caspase-8-dependent apoptosis. 
a
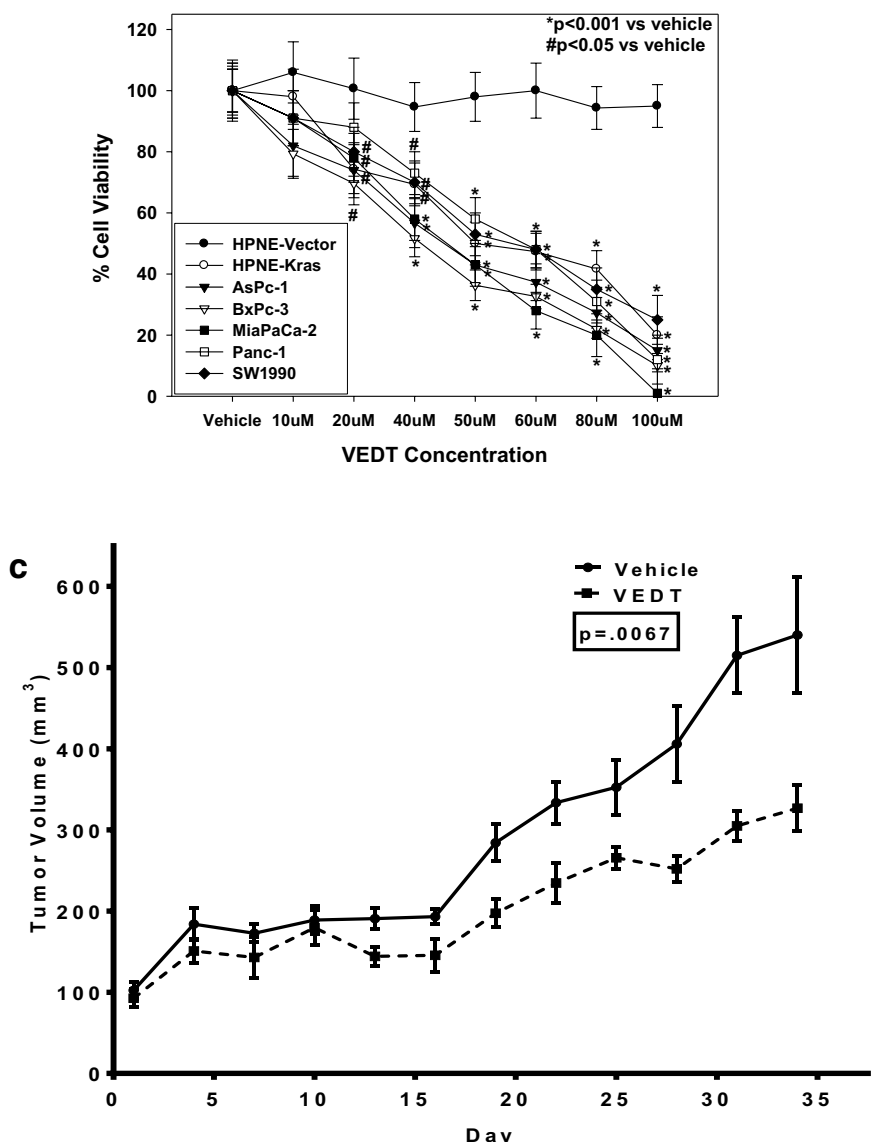

b

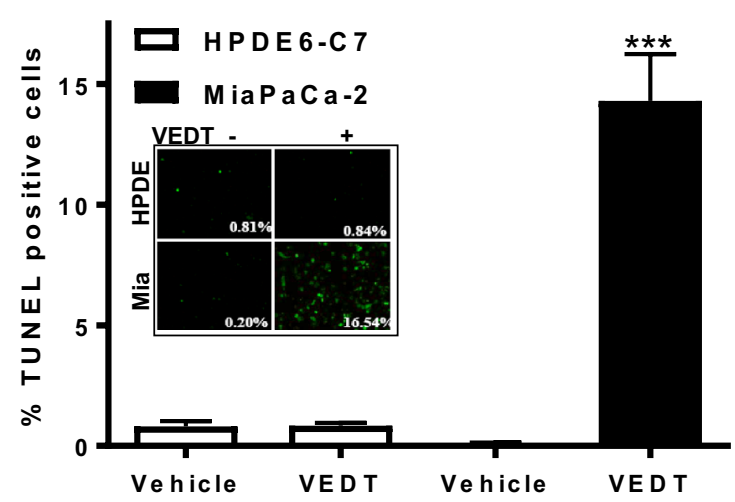

d

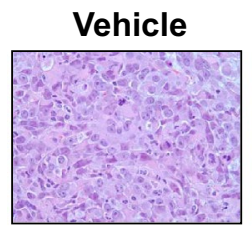

VEDT

$H \& E$
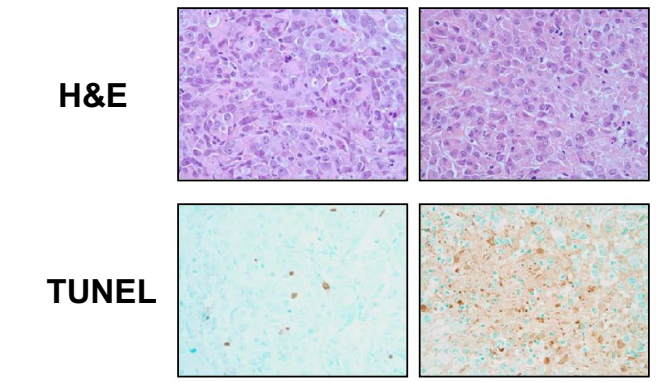

Cleaved

Caspase 8

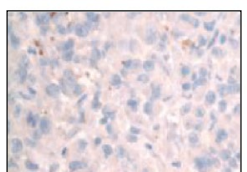

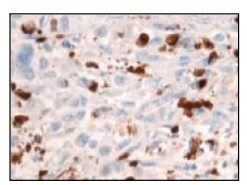

Fig. 1 The effects of VEDT on survival, apoptosis induction, and tumor tissues in mice. a Effect of VEDT dose response on survival at $72 \mathrm{~h}$ in panel of human pancreatic cancer cell lines (AsPc-1, BXPc-3, MiaPaCa-2, Panc-1, and SW1990) and a pair of immortalized HPNE containing vector alone (HPNE-V) or transformed with oncogenic KRAS (HPNE-KRAS). Points, means; bars, standard error $\left(n=3-5,{ }^{*} P<.001,{ }^{\#} P<.05\right)$. $\mathbf{b}$ Effect of $\delta$-tocotrienol (VEDT; $20 \mu \mathrm{M}$ ) on induction of apoptosis, as measured by TUNEL staining in HPDE6-C7 immortalized human pancreatic ductal epithelial cells and MiaPaCa-2 pancreatic cancer cells. Ethanol served as vehicle control. VEDT significantly induced apoptosis in MiaPaCa-2 cells. Columns, means; bars, standard deviation $\left(n=4,{ }^{* *} P<.001\right)$. c Growth inhibition of subcutaneous MiaPaCa-2 xenografts in NIH-III mice treated orally twice daily with $200 \mathrm{mg} / \mathrm{kg}$ VEDT. Olive oil served as vehicle control. Points, means; bars, standard deviation $(n=5, P<.007)$. d Effect of VEDT on apoptosis (TUNEL) and cleaved caspase 8 in formalin-fixed, paraffin-embedded MiaPaCa-2 xenograft tumor tissues in mice. H\&E, hematoxylin and eosin. VEDT significantly induced apoptosis $(P<.05)$ compared with vehicle-treated mice $(n=5)$

\section{VEDT augments TRAIL-mediated apoptosis in human pancreatic cancer in vitro and in vivo}

If VEDT-induced apoptosis is caspase-8-dependent, we speculated that adding exogenous recombinant TRAIL to VEDT treatment would result in enhanced apoptosis induction. To test this hypothesis, we treated 4 human pancreatic cancer cell lines (MiaPaCa-2, BxPC3, SW1990, and Panc-1) with VEDT alone, TRAIL alone, or both drugs combined and then accessed cell survival, caspase- 3 enzyme activity, and apoptosis. As presented in Fig. 3a, the combination of VEDT at concentrations of 10 to $50 \mu \mathrm{M}$ with TRAIL (25 or $50 \mathrm{ng} / \mathrm{mL}$ ) was more effective in decreasing tumor cell number than either agent alone. For example, in MiaPaCa-2, both VEDT alone (at $25 \mu \mathrm{M}$ ) and TRAIL alone (at $25 \mathrm{ng} / \mathrm{mL}$ ) decreased cell numbers by $15 \%$ and $30 \%$, respectively. However, combining the 2 agents reduced cell numbers by $>50 \%$; more than the sum of each agent's effects alone. Measuring caspase-3 enzyme activity further highlights the effects of combining VEDT and TRAIL on apoptosis induction. Figure $3 \mathrm{~b}$ shows that the combination of $50 \mu \mathrm{M}$ VEDT and $25 \mathrm{ng} /$ mL TRAIL more effectively activated caspase- 3 enzyme activity than either agent alone in all pancreatic cancer cell lines examined. For example, in SW1990 cells, both VEDT alone and TRAIL alone increased enzyme 


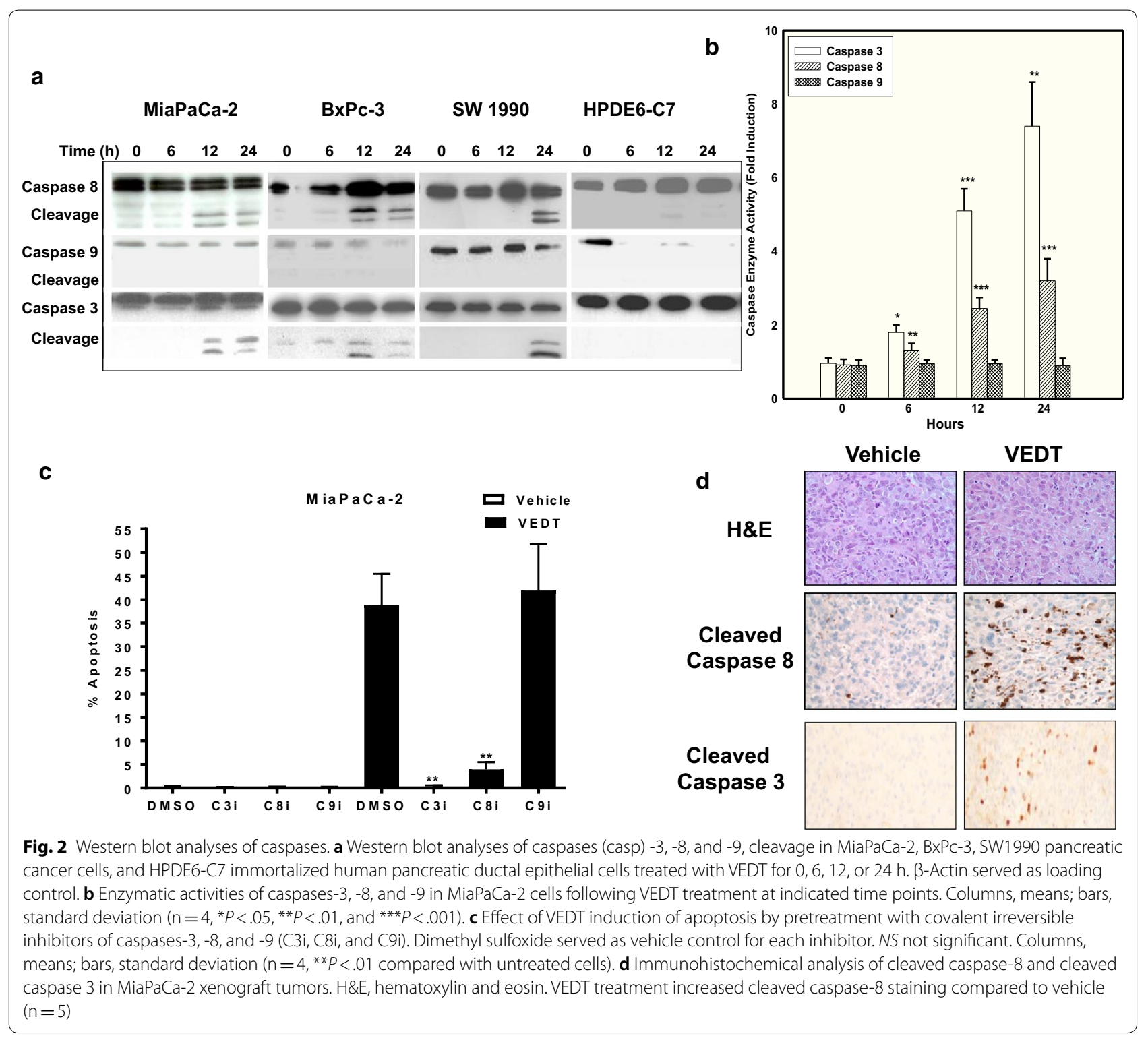

activity by 250 - and 300-fold over controls; however, the 2 agents combined increased enzyme activity by $>1000$-fold, which was greater than the sum of the effects of each agent alone. Using Western blotting, we also detected the strongest bands of cleaved caspases and poly ADP ribose polymerase (PARP) or the most reduction of procaspases and PARP in cells exposed to VEDT + TRAIL compared with VEDT or TRAIL alone (Fig. 3c). Moreover, we used annexin V staining to detect apoptosis in MiaPaCa-2 and Panc-1 cells exposed to VEDT + TRAIL. During 24-h treatment, VEDT + TRAIL combined was much more effective in inducing apoptosis (44\% and 49\%) than TRAIL (15\% and $23 \%$ ) or VEDT (20\% and $25 \%$ ) alone (Fig. $3 \mathrm{~d}$ and
Additional file 1: Figure S1). Collectively, these results clearly indicate that VEDT synergized with TRAIL to augment induction of apoptosis in human pancreatic cancer cells. To verify these findings in vivo, we examined VEDT's antitumor and proapoptotic activity in a human pancreatic cancer xenograft mouse model. MiaPaCa-2 cells were injected subcutaneously into Athymic nude mice and allowed to reach a volume of $100 \mathrm{~mm}^{3}$, and the single-drug treatments and the combination were given for 4 weeks. Tumor volume was recorded every week, and after 4 weeks, the tumor weights were recorded and the tumor tissues were processed to analyze c-FLIP and apoptotic protein expression by Western Blot. Tumor volume and 


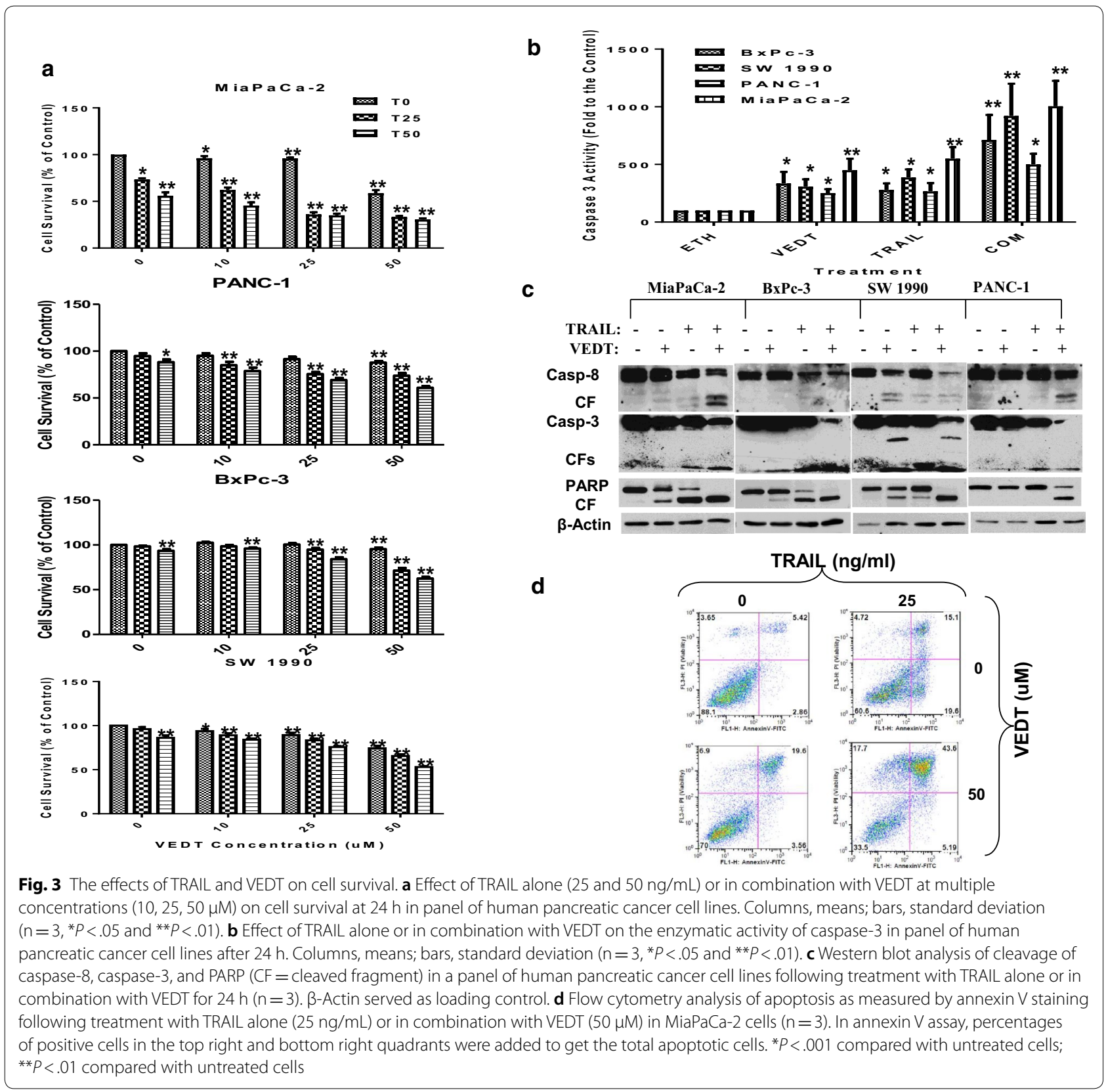

weight were significantly reduced in mice previously treated with TRAIL $\left({ }^{\mathrm{c}} P<.001\right.$ and $\left.{ }^{\mathrm{a}} P<.02\right)$ and VEDT $\left({ }^{\mathrm{c}} P<.001\right.$ and $\left.{ }^{\mathrm{a}} P<.02\right)$ for 4 weeks compared to those treated with vehicle (Fig. 4a, b). However, the combination of the 2 drugs resulted in a more significant inhibition of tumor volume $\left({ }^{\mathrm{c}} P<.001\right)$ and weight $\left({ }^{\mathrm{b}} P<.01\right)$ than for tumors treated with vehicle or either drug alone $\left({ }^{\mathrm{d}} P<.02\right.$ and $\left.{ }^{\mathrm{c}} P<.05\right)$. The Western blot data show that TRAIL and VEDT induced apoptosis (cleaved caspase- 8 , cleaved caspase- 3 , and cleaved PARP), and the combination induced greater apoptosis in the tumor tissues than either drug alone (Fig. 4c). VEDT but not TRAIL depleted the c-FLIP expression in tumor tissues compared to vehicle. However, combining the 2 drugs profoundly depleted the c-FLIP expression in tumor tissues (Fig. 4c). The histological data in tumor tissues further confirmed that VEDT significantly enhanced the TRAIL-induced apoptosis (cleaved caspase-8) and inhibition of tumor cell proliferation (Ki-67), as depicted in Figs. 4d, e. 


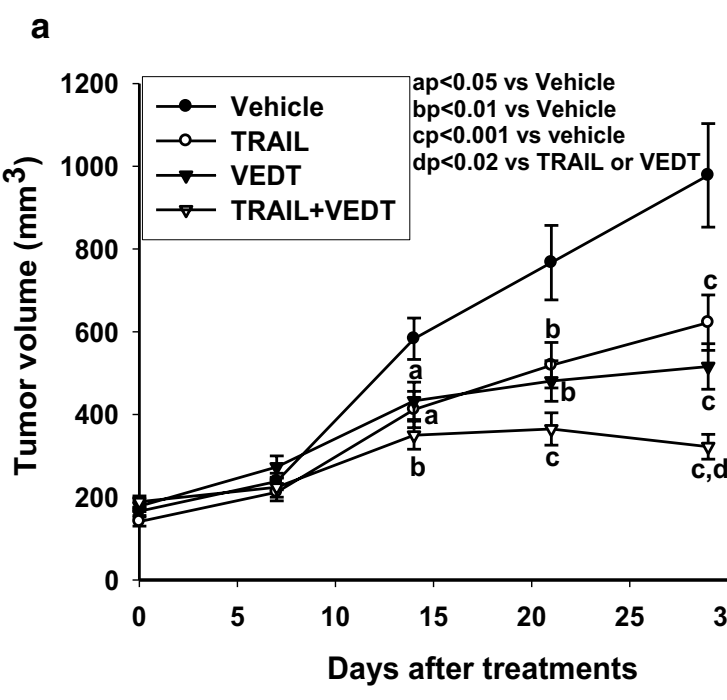

b

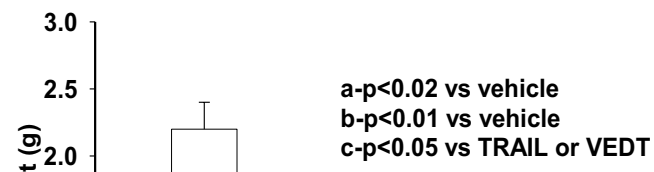

d

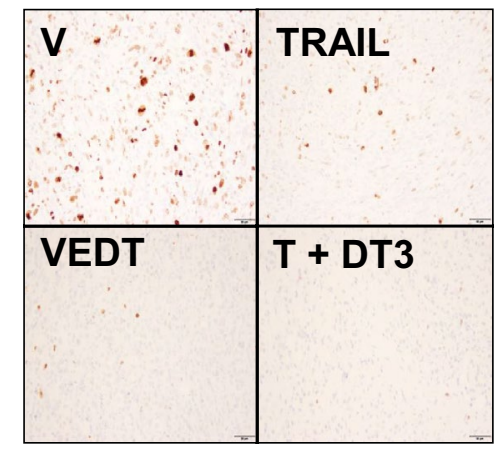

e

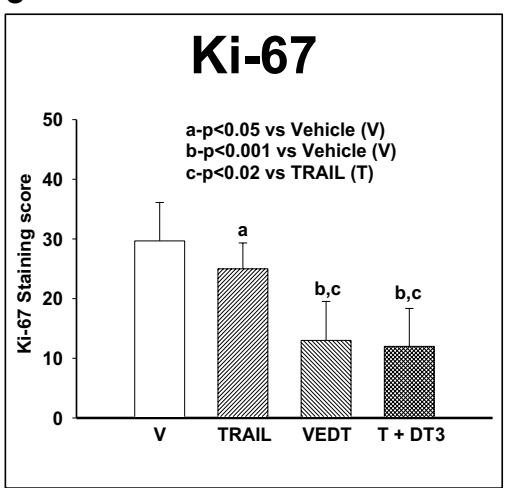

c

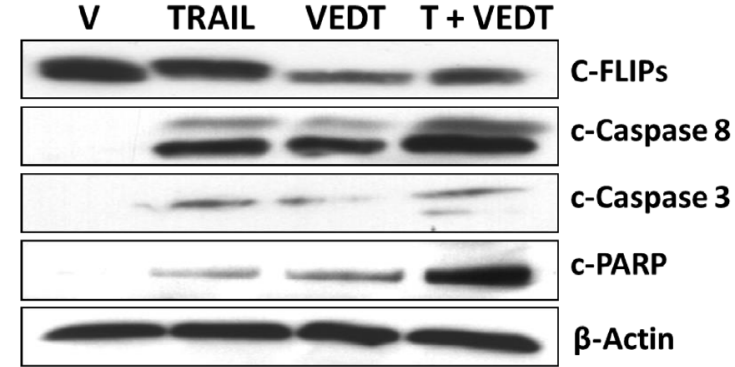

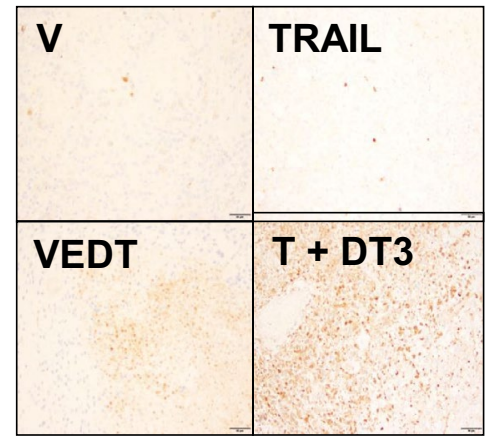

\section{Cleaved Caspase 3}
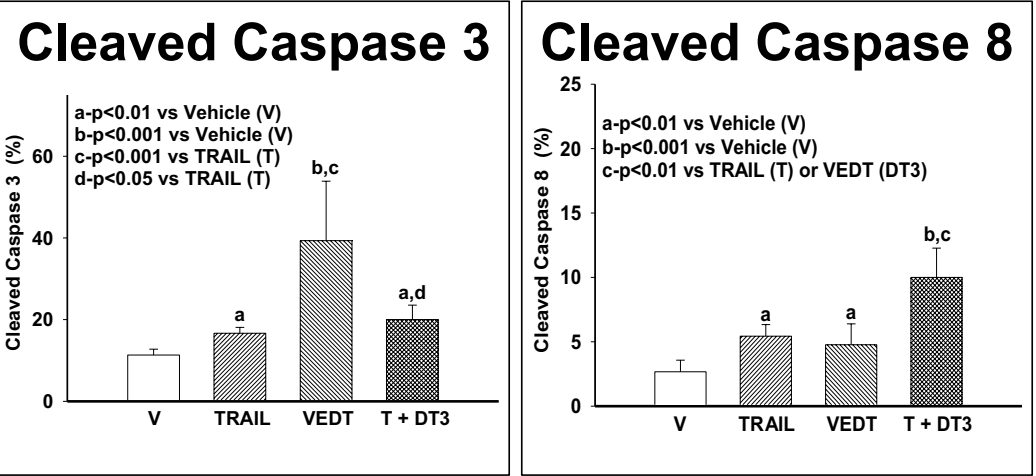
(See figure on previous page.)

Fig. 4 The effects of TRAIL and VEDT on tumor volume. a Effect of TRAIL ( $20 \mu \mathrm{g} / \mathrm{Kg}$ intraperitoneally) on alternate days and VEDT (200 mg/kg, Orally) twice a day and combination of the two drugs for 4 weeks on MiaPaPa-2 tumor volume in Athymic nude mice. The tumor volume significantly reduced in TRAIL and VEDT treated mice for 4 weeks compared to vehicle $\left({ }^{C} P<.001\right.$ and $\left.{ }^{C} P<.001\right)$. However the combination of the two drugs resulted in a more significant inhibition of tumor volume compared to vehicle $\left({ }^{\mathrm{C}} P<.001\right)$ or either drug alone $\left({ }^{\mathrm{d}} P<.02\right)$. b Effect of TRAIL $(20 \mu \mathrm{g} / \mathrm{Kg}$ intraperitoneally) on alternate days and VEDT ( $200 \mathrm{mg} / \mathrm{kg}$, Orally) twice a day and combination of the two drugs for 4 weeks on MiaPaPa-2 tumor weight in athymic nude mice. The tumor weights were significantly reduced in TRAIL and VEDT ( $\left.{ }^{\mathrm{a}} P<.02\right)$ treated mice for 4 weeks compared to vehicle $\left({ }^{\mathrm{a}} P<.02\right.$ and $\left.{ }^{\mathrm{a} 0} P<.02\right)$. However, the combination of the two drugs resulted in a more significant inhibition of tumor weight compared to vehicle $\left({ }^{b} P<.01\right)$ or either drug alone $\left({ }^{c} P<.05\right)$. $c$ Western blot analyses of cleaved caspase-8, cleaved caspase-3, cleaved PARP, and c-FLIPs in tumor tissues following treatment with TRAIL alone or in combination with VEDT for 4 weeks $(n=5)$. $\beta$-Actin served as loading control. TRAIL and VEDT alone induced apoptosis (elevated cleaved caspase-8, cleaved caspase-3, and cleaved PARP). Greater induction of apoptosis was noted in tumor tissues following combined drug treatment than with either drug alone. VEDT alone and in combination with TRAIL but not TRAIL alone depleted tumor tissue c-FLIP ${ }_{s}$ expression. d Histological data depicting the Ki-67, cleaved caspase-3, and cleaved caspase-8 in tumor tissues following treatment with TRAIL (T) alone or in combination with VEDT (DT3) for 4 weeks $(n=5)$. e Greater and significant induction of apoptosis (cleaved caspase-8, ${ }^{b} p<.001$ ) and inhibition of tumor cell proliferation (Ki-67, ${ }^{b} p<.001$ ) was noted in tumor tissues following combined drug treatment than with either drug alone. VEDT alone significantly induced cleaved caspase 3 compared to vehicle $\left({ }^{b} P<.001\right)$ and was greater than TRAIL-alone treatment $\left({ }^{\mathrm{c}} P<.001\right)$. The combination significantly induced cleaved caspase 3 compared to vehicle $\left({ }^{\mathrm{a}} P<.01\right)$ and compared to TRAIL alone $\left({ }^{\mathrm{d}} P<.05\right)$

\section{VEDT induces apoptosis and augments TRAIL activity through down-regulation of C-FLIP ${ }_{S}$ in human pancreatic cancer cells}

The mechanisms by which agents augment TRAILinduced apoptosis include modulation of proteins upstream to caspase- 8 activation. These mechanisms include induction of the death receptors DR4 and/or DR5, decreased expression of decoy receptors DCR1, DCR2, and DCR3, and decreased expression of the short isoform of c-FLIP (c-FLIP $)$, which inhibits apoptosis by preventing the recruitment of caspase- 8 into the death-inducing signaling complex. Thus we determined whether VEDT modulated DCR1, DCR2, DCR3, DR4, DR5, or c-FLIP ${ }_{\mathrm{s}}$ expression in human pancreatic cancer cells by Western blot analysis. We detected a consistent time-dependent decrease in $\mathrm{FLIP}_{\mathrm{s}}$ expression that preceded VEDT-induced activation of caspase- 8 in MiaPaCa-2, BxPC-3, and SW1990 cells exposed to VEDT, which occurred at $6 \mathrm{~h}$ and was sustained for at least $16 \mathrm{~h}$ (Fig. 5a). In contrast, there was no consistent modulation of DCR1, DCR2, DCR3, DR4, or DR5 by VEDT.

We next investigated whether inhibition of c-FLIP $_{s}$ is required for induction of apoptosis by VEDT using MiaPaCa-2 cells transfected with pCMV6-AV-GFP vectorcontaining c-FLIP $\mathrm{s}$ tagged with GFP. Figure $5 \mathrm{~b}$ shows that we observed a statistically significant induction of apoptosis in mock and vector-transfected cells treated with VEDT $(P<.01$ and $P<.001)$. Importantly, transient overexpression of $\mathrm{c}-\mathrm{FLIP}_{\mathrm{s}}$ not only abrogated VEDT-induced apoptosis compared with vehicle (not significant) but also rescued endogenous c-FLIP $_{s}$ inhibition compared with vector transfection. To further study the role of c-FLIP , we created MiaPaCa-2 cells stably overexpress-

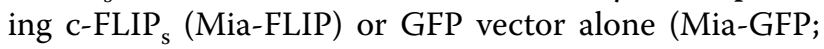
Additional file 2: Figure S2B-E). This enforced ectopic overexpression of $\mathrm{c}-\mathrm{FLIP}_{\mathrm{s}}$ significantly abrogated VEDT induction of caspase- 8 enzymatic activity and inhibition of survival (Fig. 5c). Moreover, c-FLIP s $_{\text {overexpres- }}$ sion in MiaPaca- 2 cells resulted in inhibition of VEDT augmentation of TRAIL-induced inhibition of cell survival in pancreatic cancer cells. For example, TRAIL $(25 \mathrm{ng} / \mathrm{L})$ and VEDT $(25 \mu \mathrm{M})$ treatment of MiaPaCa-2 cells with GFP vector decreased cell numbers by $30 \%$ and $20 \%$, respectively, whereas the combination decreased cell number by $45 \%$. In contrast, the same concentration of the agents in MiaPaCa-2 cells expressing c-FLIP ${ }_{s}$ decreased cell numbers by $10 \%$ and $5 \%$, respectively, with the combination decreasing cell numbers by only $20 \%$ in these cells (Fig. 5d).

\section{VEDT down-regulates c-FLIP ${ }_{s}$ through promoting ubiquitin/proteasome-mediated degradation}

To determine how VEDT regulates c-FLIP , we investi-

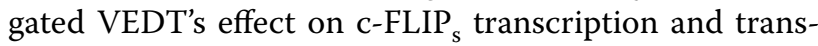
lation. Regulation of $\mathrm{c}-\mathrm{FLIP}_{\mathrm{s}}$ has been shown to occur at the level of transcription and translation, as well as post-transitionally at the protein level [24]. To this end, mRNA levels from VEDT-treated MiaPaCa-2 and BxPc-3 cells were analyzed by quantitative PCR at $6 \mathrm{~h}$, at which point protein levels of $\mathrm{c}-\mathrm{FLIP}_{\mathrm{s}}$ seemed to first decrease.

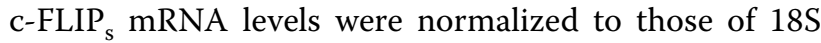
rRNA (internal control). At $6 \mathrm{~h}$ after VEDT treatment, we observed that $\mathrm{c}$-FLIP $\mathrm{s}_{\mathrm{s}}$ messenger RNA (mRNA) levels had not decreased but had actually increased versus baseline (Fig. 6a).

To validate our findings, we investigated the ability of VEDT to down-regulate c-FLIP s protein expression in the absence of mRNA translation using the protein synthesis inhibitor cyclohexamide. VEDT was found to accelerate c-FLIP $_{\mathrm{s}}$ turnover compared with turnover observed with cyclohexamide alone (Fig. 6b). Next, we sought to identify whether proteasomal 


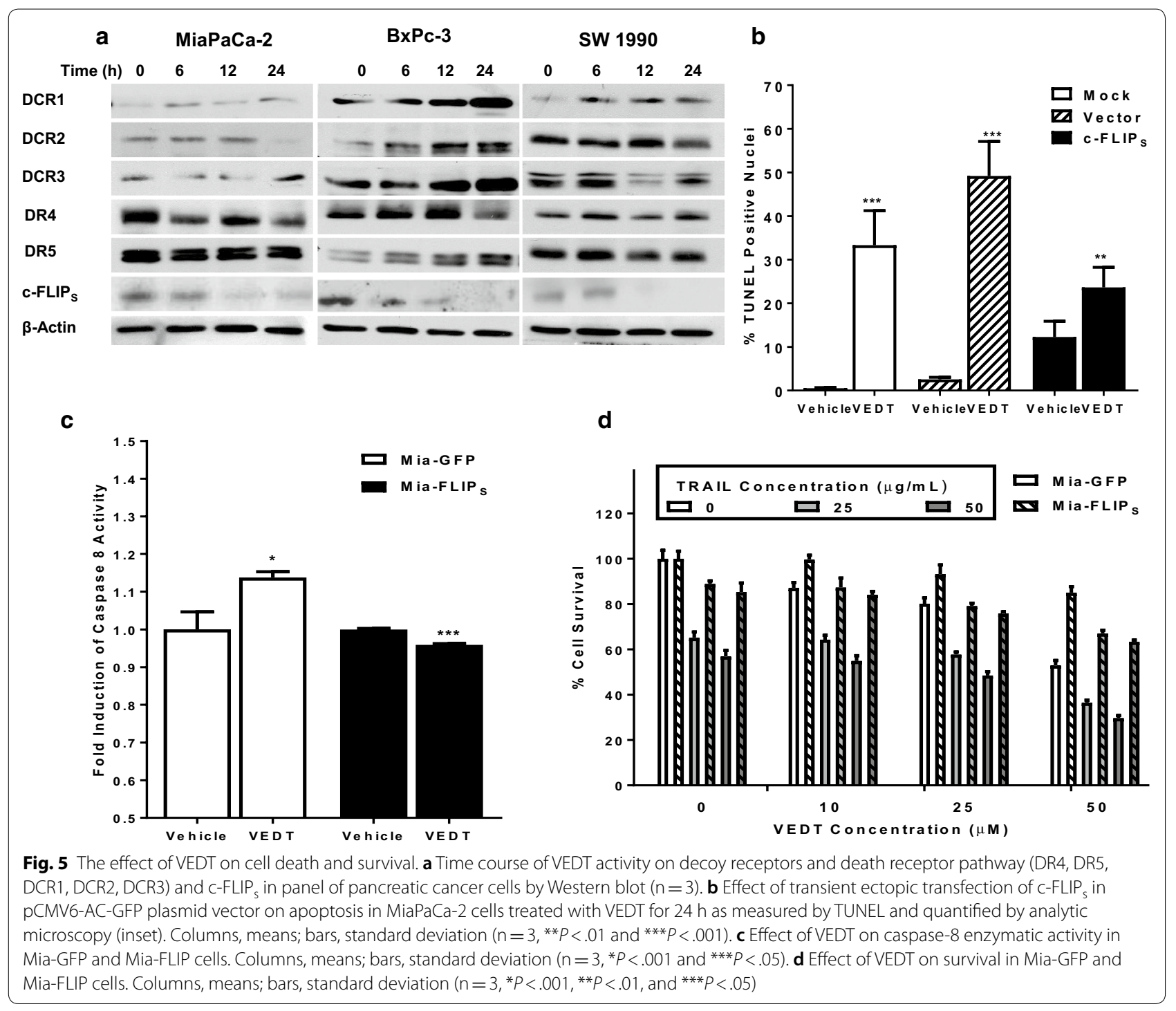

degradation could be implicated in VEDT down-regulation of c-FLIP . We found that inhibition of c-FLIP $_{s}$ could be prevented by pretreatment with the pan-protease inhibitor MG132 in all cell lines tested (Fig. 6c). Because ubiquitination has been identified as an important event associated with proteasomal degradation [25], we next transfected human influenza HA-tagged ubiquitin into MiaPaCa-2 cells stably overexpressing GFP-tagged c-FLIP. . Using co-immunoprecipitation techniques, we evaluated the fraction of ubiquitinbound c-FLIP. As indicated in Fig. 6d, treatment with VEDT resulted in a marked shift in the fraction of ubiquitin-bound c-FLIP ${ }_{\mathrm{s}}$ in the presence of MG-132 when compared to that of MG-132 alone. Collectively, these data support the concept that VEDT decreased c-FLIP levels through promoting ubiquitin/proteasome-mediated degradation of c-FLIP.
Potencies of vitamin E compounds in inhibiting cell survival and enhancing cell death receptor-mediated apoptosis are associated with their abilities to down-regulate c-FLIP

We previously demonstrated that VEDT is the most bioactive of all of the naturally occurring vitamin $\mathrm{E}$ ana$\operatorname{logs}$ (Additional file 3: Figure S3A) [16]. Here, we report that VEDT is the most powerful vitamin $\mathrm{E}$ inhibitor of cell survival and c-FLIP protein expression in pancreatic cancer cells. Of note, c-FLIP down-regulation was directly associated with the ability of each vitamin $\mathrm{E}$ compound to inhibit cell survival (Additional file 3: Figure S3B, C). In addition, VEDT also augmented TRAIL-induced cell death in HPNE-Kras cells but not in normal HPNE-vector cells (Additional file 2: Figure S2A). 


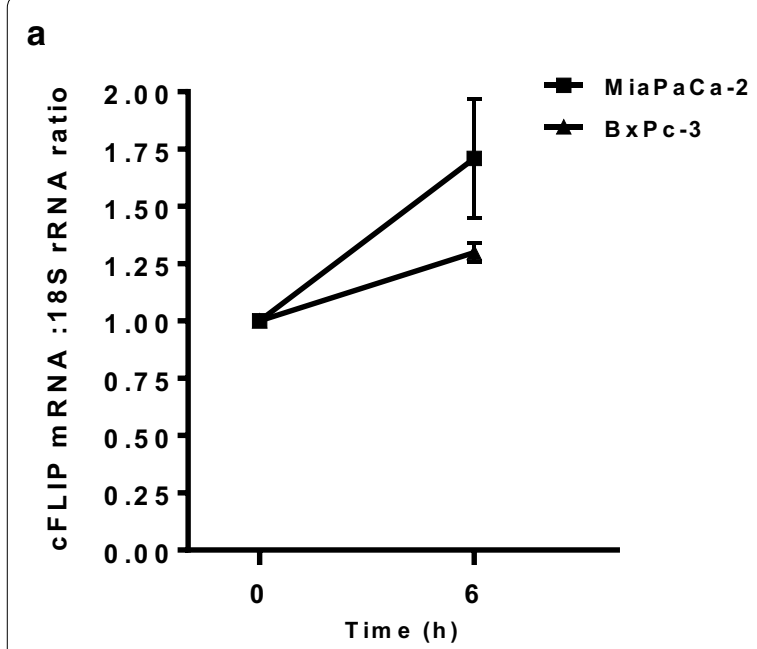

b

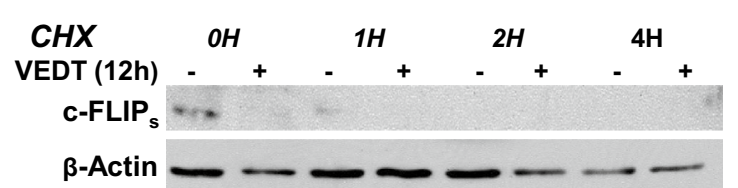

d

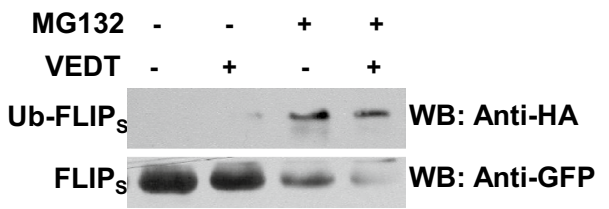

C

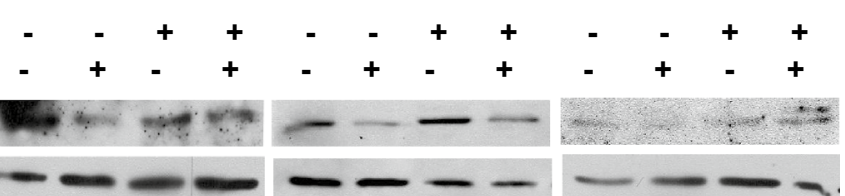

Fig. 6 The effect of VEDT on c-FLIP. a Effect of VEDT treatment on c-FLIP messenger RNA levels in MiaPaCa-2 and BxPc-3 cells at 6 h. 185 rRNA served as internal control for each sample $(n=3)$. b Half-life of $c-F L I P_{s}$ protein in MiaPaCa-2 cells as determined by cyclohexamide $(C H X)(25 \mu g /$ $\mathrm{ml}$ ) pretreatment for the indicated duration, following 12-hour treatment with either vehicle (ethanol) or VEDT ( $n=3$ ). $\mathbf{c}$ Effect of MG132 protease inhibitor on c-FLIP protein levels in presence or absence of VEDT in a panel of pancreatic cancer cell lines (MiaPaCa-2, SW1990, BxPc-3 and Panc-1). The cells were pretreated with MG132 $(25 \mu \mathrm{M})$ for $6 \mathrm{~h}$ followed by VEDT treatment for $24 \mathrm{~h}(\mathrm{n}=3)$. $\mathbf{d}$ Effect of MG132 protease inhibitor on ubiquitin-bound c-FLIP in the presence or absence of VEDT in MiaPaCa-2 cells. The cells were pretreated with MG132 (25 $\mu \mathrm{M})$ for $6 \mathrm{~h}$ followed by VEDT treatment for $24 \mathrm{~h}(\mathrm{n}=3)$

\section{Discussion}

Pancreatic cancer is highly aggressive, with only $6 \%$ of patients surviving 5 years after diagnosis. Suppression of programed cell death is a hallmark of this cancer, which it displays as increased viability and resistance to cytotoxic therapies [26]. One example of this resistance to therapy is pancreatic cancer's varied sensitivity to TRAIL, a tumor-selective cytokine, which activates the extrinsic apoptotic pathway [27-31]. Therefore, there is an important need for proapoptotic agents that can sensitize pancreatic ductal adenocarcinoma cells to TRAIL and thereby overcome pancreatic cancer resistance to apoptosis. One intriguing finding that has been shown consistently by our group and others is the selective killing of pancreatic cancer cells by VEDT [5, 16, 19-21]. We have also shown selective induction of apoptosis by VEDT of pancreatic-transformed and malignant epithelial cells but not normal immortalized human pancreatic ductal epithelial cells $[16,19]$. Additionally, our animal studies showed that VEDT not only caused a statistically significant inhibition of tumor growth but also resulted in apoptosis of tumor tissues [16, 20,21]. These results clearly demonstrate that induction of apoptosis is implicated in the antitumor activity of VEDT.

In the current study, we found that VEDT alone triggered a caspase-8-dependent apoptosis in pancreatic cancer cells; however, when combined with TRAIL, VEDT significantly augmented and potentiated the TRAIL-induced apoptosis of pancreatic cancer cells. Specifically, we were able to demonstrate in vitro and in vivo increased cleaved caspase- 8 and caspase- 3 and induction of apoptotic cell death with VEDT treatment versus controls. Conversely, pharmacological inhibition of caspase- 8 and caspase- 3 demonstrated significant attenuation of VEDT-induced apoptosis. Together, these results strongly suggest that VEDT induces apoptosis through activation of the caspase- 8 cascade. The role of caspase- 8 in death receptor-mediated apoptosis has been extensively studied [24, 32, 33]. Interestingly, whereas pancreatic cancer cells have been shown 
to express all of the proteins of the extrinsic apoptotic pathway, most cell lines remain relatively insensitive to TRAIL-induced apoptosis. Both recombinant and antibody-based TRAIL therapies have been developed to date for the treatment of many cancers, but resistance to death receptor-mediated apoptosis remains a significant barrier in the field of pancreatic cancer [34].

A possible molecular target for VEDT is c-FLIP ${ }_{s}$, an inhibitor of caspase- 8 in pancreatic cancer cells. We had shown that VEDT but not tocopherols augment TRAIL activity (unpublished data). Our data show that VEDT decreased c-FLIP ${ }_{\mathrm{s}}$ levels without consistently modulating the expression of decoy death receptors 1, 2, and 3 or death receptors 4 and 5 . Furthermore, VEDT was found to inhibit c-FLIP ${ }_{\mathrm{s}}$ expression and induce caspase-8-dependent apoptosis in pancreatic cancer cells, followed by caspase- 3 and PARP1 cleavage in a timedependent manner. The activation of caspases- 8 and -3 were required for VEDT induction of apoptosis, as demonstrated by rescue with specific caspase inhibitors. Moreover, the growth of pancreatic xenograft tumors in mice was significantly inhibited when treated with VEDT. This inhibition was also accompanied by an induction of apoptosis in tumors and depletion of $\mathrm{c}^{-F L I P}$ protein expression. Although VEDT inhibited c-FLIP protein levels by $6 \mathrm{~h}$, mRNA levels were actually increased at this time point, suggesting that VEDT may be inhibiting c-FLIP $\mathrm{s}_{\mathrm{s}}$ through protein degradation. From these analyses, we concluded that the mechanism of c-FLIP ${ }_{s}$ down-regulation is unlikely caused by transcriptional repression but rather an ubiquitin-mediated, proteasome-dependent process. Moreover, ferroptosis is a newly discovered type of cell death that differs from traditional apoptosis and necrosis and results from irondependent lipid peroxide accumulation and autophagy $[35,36]$. Pancreatic ductal adenocarcinoma with a mutant KRas gene is more susceptible to ferroptosis, and it might be related to the tumorigenesis of pancreatic carcinoma [37]. Therefore, VEDT may kill pancreatic cancer cells through ferroptosis. This possibility will be investigated in our future studies.

\section{Conclusions}

We showed that VEDT decreased c-FLIP levels by promoting ubiquitin/proteasome-mediated degradation of c-FLIP. In summary, our data indicate that VEDT down-regulates c-FLIP , an inhibitor of caspase- 8 activation through protein degradation, and induces apoptosis through activation of caspase- 8 and caspase- 3 . This works suggests that VEDT should be evaluated for targeting programed cell death in pancreatic cancer cells.

\section{Additional files}

Additional file 1: Fig. S1. Chemical structures of vitamin E analogs and effect of 8 members of the vitamin E family on cell survival in MiaPaCa-2 cells. (A) Chemical structures of the vitamin E analogs. (B) Effect of the 8 members of the vitamin $E$ family on cell survival in MiaPaCa-2 cells. Points, means; bars, standard error $\left(n=3-5,{ }^{*} P<.001,{ }^{* *} P<.01\right)$. (C) Effect of the 8 members of the vitamin E family on c-FLIP expression in MiaPaCa-2 cells $(n=3)$.

Additional file 2: Fig. S2. Effects of VEDT and TRAIL on cell death and Western blot analyses. (A) Effect of VEDT $(50 \mu \mathrm{M})$ and TRAIL $(25 \mathrm{ng} / \mathrm{mL})$ alone and in combination on cell death (Trypan blue) of immortalized human pancreatic normal epithelial (HPNE-vector) cells and HPNE-Kras cells. VEDT, TRAIL, or the combination of the 2 drugs did not cause significant cell death in HPNE-vector cells $(n=3-5)$. VEDT and TRAIL alone significantly induced cell death compared to vehicle $\left({ }^{\mathrm{a}} P<.02\right.$ and ${ }^{\mathrm{b}} P<.05$, respectively) in HPNE-Kras cells $(n=3-5)$. However, greater significant cell death occurred when agents were combined than with vehicle $\left({ }^{c} P<.01\right)$ and either drug alone ( $\left.{ }^{d} P<.05\right)$. (B) Western blot analyses of endogenous and exogenous $\mathrm{C}-\mathrm{FLIP}$, protein expression in MiaPaCa-2 cells. Mock transfection and pCMV6-AC-GFP vector transfections served as internal controls, whereas $\beta$-actin served as loading control. c-FLIP ${ }_{s}$ expression is shown in parental MiaPaCa-2 cells and in MiaPaCa-2 cells stably express-

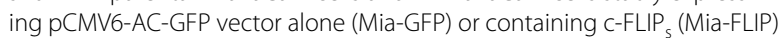
$(n=3)$. (C) VEDT inhibited c-FLIP expression in Mia-GFP cells compared to vehicle $(V)$ after $24 \mathrm{~h}$ and the expression was rescued in Mia-FLIP cells $(n=3)$. (D) VEDT (T) induced apoptosis (PARP cleavage) in (Mia-GFP) cells compared to vehicle $(V)$ after $24 \mathrm{~h}$. CF = cleaved fragment $(n=3)$ and (E) Immunofluorescence staining of apoptosis (TUNEL) show that VEDT induced apoptosis in (Mia-GFP) cells compared to vehicle (Veh) after $24 \mathrm{~h}$ and apoptosis was rescued in (Mia-FLIP) cells compared to vehicle (Veh) $(n=3)$.

Additional file 3: Fig. S3.Effects of VEDT and TRAIL on apoptosis Effects of VEDT $(50 \mu \mathrm{M})$ and TRAIL $(25 \mathrm{ng} / \mathrm{mL})$ alone and in combination on apoptosis (Annexin V/PI) of Panc-1 cells. VEDT and TRAIL induced apoptosis ( $25 \%$ and $23 \%$, respectively) compared to vehicle in Panc- 1 cells. However, greater apoptosis occurred when the 2 drugs were combined than occurred with vehicle alone (49\%) in Panc-1 cells.

\section{Abbreviations}

VEDT: Vitamin E delta-tocotrienol; c-FLIP: cellular FLICE inhibitory protein; GFP: green fluorescence protein; HPNE: human pancreatic normal epithelial; TUNEL: terminal deoxynucleotidyl transferase-mediated nick end labeling; PBS: phosphate-buffered saline; IP: intraperitoneal; ANOVA: analysis of variance; PARP: poly ADP ribose polymerase; TRAIL: tumor necrosis factor-related apoptosis-inducing ligand; FLIP: FLICE inhibitory protein; HA: hemagglutinin; SRB: sulforhodamine B.

\section{Acknowledgements}

We thank Sonya Smyk, Paul Fletcher, and Daley Drucker at H. Lee Moffitt Cancer Center and Research Institute, Tampa, FL for their editorial assistance.

\section{Authors' contributions}

RAF carried out experiments, analyzed results, and drafted the manuscript; AZ carried out experiments and helped interpret the data; CW analyzed data and helped draft the discussion; SH carried out experiments and helped interpret the data; MK carried out experiments and helped interpret the data; $\mathrm{KH}$ carried out experiments, analyzed results, and helped draft and review the manuscript; SB reviewed and interpreted the data; SS reviewed the manuscript; DC reviewed the manuscript; MM oversaw experiments, analyzed results, and helped draft, review, and finalize the manuscript. All authors read and approved the final manuscript.

\section{Funding}

The study was supported in part by National Cancer Institute/USPHS 523 Grant 1RO1 CA-129227-01A1. This work has been supported in part by the Flow Cytometry Core Facility, the Analytic Microscopy Core, the Molecular Biology Core, the Anatomic Pathology Core, and the Small Animal Modeling 
and Imaging Core at the H. Lee Moffitt Cancer Center \& Research Institute, a comprehensive cancer center designated by the National Cancer Institute, supported under NIH grant P30-CA76292.

\section{Availability of data and materials}

Data will be made available upon reasonable request.

\section{Ethics approval and consent to participate}

All experiments were carried out in accordance with guidelines set by the Animal Experimental Ethics Committee.

\section{Consent for publication}

Not applicable.

\section{Competing interests}

The authors declare that they no competing interests.

\section{Author details}

1 Gastrointestinal Oncology Program, Department of Gastrointestinal Oncology, H. Lee Moffitt Cancer Center and Research Institute, 12902 Magnolia Drive, Tampa, FL 33612, USA. ${ }^{2}$ Department of Life Science and Technology, University of Electronic Science and Technology of China, Chengdu, China. ${ }^{3}$ Department of Breast Oncology, Tianjin Medical University Cancer Institute and Hospital, Tianjin, China. ${ }^{4}$ Department of Biochemistry and Molecular Biology, College of Medicine, University of Nebraska Medical Center, Omaha, NB, USA. ${ }^{5}$ Department of Anatomical Pathology, H. Lee Moffitt Cancer Center and Research Institute, Tampa, FL, USA. ${ }^{6}$ Drug Discovery Program, H. Lee Moffitt Cancer Center and Research Institute, Tampa, FL, USA.

Received: 15 October 2018 Accepted: 28 May 2019

Published online: 22 July 2019

\section{References}

1. Jemal A, Ward EM, Johnson CJ, Cronin KA, Ma J, Ryerson B, Mariotto A, Lake AJ, Wilson R, Sherman RL, et al. Annual report to the nation on the status of cancer, 1975-2014, featuring survival. J Natl Cancer Inst. 2017. https://doi.org/10.1093/jnci/djx030.

2. Ma J, Siegel $R$, Jemal A. Pancreatic cancer death rates by race among US men and women, 1970-2009. J Natl Cancer Inst. 2013;105(22):1694-700

3. Rahib L, Smith BD, Aizenberg R, Rosenzweig AB, Fleshman JM, Matrisian LM. Projecting cancer incidence and deaths to 2030: the unexpected burden of thyroid, liver, and pancreas cancers in the United States. Cancer Res. 2014;74(11):2913-21.

4. Siegel R, Ma J, Zou Z, Jemal A. Cancer statistics, 2014. CA Cancer J Clin. 2014;64(1):9-29.

5. Kunnumakkara AB, Sung B, Ravindran J, Diagaradjane P, Deorukhkar A, Dey S, Koca C, Yadav VR, Tong Z, Gelovani JG, et al. \{Gamma\}-tocotrienol inhibits pancreatic tumors and sensitizes them to gemcitabine treatment by modulating the inflammatory microenvironment. Cancer Res. 2010;70(21):8695-705.

6. Yin T, Wei H, Gou S, Shi P, Yang Z, Zhao G, Wang C. Cancer stem-like cells enriched in panc-1 spheres possess increased migration ability and resistance to gemcitabine. Int J Mol Sci. 2011;12(3):1595-604.

7. Fulda S, Debatin KM. Extrinsic versus intrinsic apoptosis pathways in anticancer chemotherapy. Oncogene. 2006;25(34):4798-811.

8. Porter AG, Janicke RU. Emerging roles of caspase-3 in apoptosis. Cell Death Differ. 1999;6(2):99-104.

9. Elmore S. Apoptosis: a review of programmed cell death. Toxicol Pathol. 2007;35(4):495-516.

10. Lowe SW, Lin AW. Apoptosis in cancer. Carcinogenesis. 2000;21 (3):485-95.

11. Vogler M, Walczak H, Stadel D, Haas TL, Genze F, Jovanovic M, Bhanot U, Hasel C, Moller P, Gschwend JE, et al. Small molecule XIAP inhibitors enhance TRAIL-induced apoptosis and antitumor activity in preclinical models of pancreatic carcinoma. Cancer Res. 2009;69(6):2425-34.

12. Yuan K, Sun Y, Zhou T, McDonald J, Chen Y. PARP-1 regulates resistance of pancreatic cancer to TRAIL therapy. Clin Cancer Res. 2013;19(17):4750-9.

13. Zhou W, Shi J, Niu Z, Luo H, Tian H, Gao J, Yu F, Li S. SmacN7 enhances the sensitivity of pancreatic cancer cells to tumor necrosis factor-related apoptosis-inducing ligand or gemcitabine. Oncol Lett. 2013;5(6):1760-4.
14. Aggarwal BB, Sundaram C, Prasad S, Kannappan R. Tocotrienols, the vitamin E of the 21st century: its potential against cancer and other chronic diseases. Biochem Pharmacol. 2010;80(11):1613-31.

15. Aggarwal B, Nesaretnam K. Vitamin E tocotrienols: life beyond tocopherols. Genes Nutr. 2012;7(1):1.

16. Husain K, Francois RA, Yamauchi T, Perez M, Sebti SM, Malafa MP. Vitamin E delta-tocotrienol augments the antitumor activity of gemcitabine and suppresses constitutive NF-kappaB activation in pancreatic cancer. Mol Cancer Ther. 2011;10(12):2363-72.

17. Ling MT, Luk SU, Al-Ejeh F, Khanna KK. Tocotrienol as a potential anticancer agent. Carcinogenesis. 2012;33(2):233-9.

18. Loganathan R, Selvaduray KR, Nesaretnam K, Radhakrishnan AK. Tocotrienols promote apoptosis in human breast cancer cells by inducing poly(ADP-ribose) polymerase cleavage and inhibiting nuclear factor kappa-B activity. Cell Prolif. 2013;46(2):203-13.

19. Hodul PJ, Dong Y, Husain K, Pimiento JM, Chen J, Zhang A, Francois R, Pledger WJ, Coppola D, Sebti SM, et al. Vitamin E delta-tocotrienol induces p27(Kip1)-dependent cell-cycle arrest in pancreatic cancer cells via an E2F-1-dependent mechanism. PLoS ONE. 2013;8(2):e52526.

20. Husain K, Centeno BA, Chen DT, Fulp WJ, Perez M, Zhang Lee G, Luetteke N, Hingorani SR, Sebti SM, Malafa MP. Prolonged survival and delayed progression of pancreatic intraepithelial neoplasia in LSLKrasG12D/+:Pdx-1-Cre mice by vitamin E delta-tocotrienol. Carcinogenesis. 2013;34(4):858-63.

21. Husain K, Centeno BA, Chen DT, Hingorani SR, Sebti SM, Malafa MP. Vitamin E delta-tocotrienol prolongs survival in the LSL-KrasG12D/+;LSLTrp53R172H/+;Pdx-1-Cre (KPC) transgenic mouse model of pancreatic cancer. Cancer Prev Res (Phila). 2013;6(10):1074-83.

22. Shibata A, Nakagawa K, Sookwong P, Tsuduki T, Oikawa S, Miyazawa T. delta-Tocotrienol suppresses VEGF induced angiogenesis whereas alphatocopherol does not. J Agric Food Chem. 2009;57(18):8696-704.

23. Skehan P, Storeng R, Scudiero D, Monks A, McMahon J, Vistica D, Warren JT, Bokesch H, Kenney S, Boyd MR. New colorimetric cytotoxicity assay for anticancer-drug screening. J Natl Cancer Inst. 1990;82(13):1107-12.

24. Safa AR. c-FLIP, a master anti-apoptotic regulator. Exp Oncol. 2012;34(3):176-84.

25. Lecker SH, Goldberg AL, Mitch WE. Protein degradation by the ubiquitinproteasome pathway in normal and disease states. J Am Soc Nephrol. 2006;17(7):1807-19.

26. Hanahan D, Weinberg RA. Hallmarks of cancer: the next generation. Cell. 2011;144(5):646-74

27. Chen S, Liu X, Yue P, Schonthal AH, Khuri FR, Sun SY. CCAAT/enhancer binding protein homologous protein-dependent death receptor 5 induction and ubiquitin/proteasome-mediated cellular FLICE-inhibitory protein down-regulation contribute to enhancement of tumor necrosis factor-related apoptosis-inducing ligand-induced apoptosis by dimethylcelecoxib in human non small-cell lung cancer cells. Mol Pharmacol. 2007;72(5):1269-79.

28. Karikari CA, Roy I, Tryggestad E, Feldmann G, Pinilla C, Welsh K, Reed JC, Armour EP, Wong J, Herman J, et al. Targeting the apoptotic machinery in pancreatic cancers using small-molecule antagonists of the X-linked inhibitor of apoptosis protein. Mol Cancer Ther. 2007;6(3):957-66.

29. Lin YD, Chen S, Yue P, Zou W, Benbrook DM, Liu S, Le TC, Berlin KD, Khuri FR, Sun SY. CAAT/enhancer binding protein homologous proteindependent death receptor 5 induction is a major component of SHetA2induced apoptosis in lung cancer cells. Cancer Res. 2008;68(13):5335-44.

30. Son YG, Kim EH, Kim JY, Kim SU, Kwon TK, Yoon AR, Yun CO, Choi KS. Silibinin sensitizes human glioma cells to TRAIL-mediated apoptosis via DR5 up-regulation and down-regulation of C-FLIP and survivin. Cancer Res. 2007;67(17):8274-84.

31. Sun SY, Liu X, Zou W, Yue P, Marcus Al, Khuri FR. The farnesyltransferase inhibitor lonafarnib induces CCAAT/enhancer-binding protein homologous protein-dependent expression of death receptor 5, leading to induction of apoptosis in human cancer cells. J Biol Chem. 2007;282(26):18800-9.

32. Krueger A, Baumann S, Krammer PH, Kirchhoff S. FLICE-inhibitory proteins: regulators of death receptor-mediated apoptosis. Mol Cell Biol. 2001;21(24):8247-54.

33. Yu JW, Jeffrey PD, Shi Y. Mechanism of procaspase-8 activation by c-FLIPL. Proc Natl Acad Sci USA. 2009:106(20):8169-74. 
34. Huang ZQ, Saluja AK, Dudeja V, Vickers SM, Buchsbaum DJ. Molecular targeted approaches for treatment of pancreatic cancer. Curr Pharm Des. 2011;17(21):2221-38.

35. Gao M, Monian P, Pan Q, Zhang W, Xiang J, Jiang X. Ferroptosis is an autophagic cell death process. Cell Res. 2016;26(9):1021-32.

36. Yu H, Guo P, Xie X, Wang Y, Chen G. Ferroptosis, a new form of cell death, and its relationships with tumourous diseases. J Cell Mol Med. 2017;21(4):648-57.
37. Lo M, Ling V, Wang YZ, Gout PW. The xc- cystine/glutamate antiporter: a mediator of pancreatic cancer growth with a role in drug resistance. $\mathrm{Br} J$ Cancer. 2008:99(3):464-72.

\section{Publisher's Note}

Springer Nature remains neutral with regard to jurisdictional claims in published maps and institutional affiliations.
Ready to submit your research? Choose BMC and benefit from:

- fast, convenient online submission

- thorough peer review by experienced researchers in your field

- rapid publication on acceptance

- support for research data, including large and complex data types

- gold Open Access which fosters wider collaboration and increased citations

- maximum visibility for your research: over 100M website views per year

At BMC, research is always in progress.

Learn more biomedcentral.com/submissions 